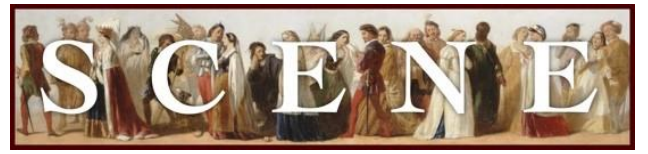

\title{
Much Ado with Italian Va-Va-"Vroom"
}

by Erin Kelly. Written on 2017-08-13. Published in 2017 Issue 2.

For the production: Much Ado about Nothing (2017, Bard on the Beach, Canada). See production details at the end of the review.

A COLLEAGUE OF MINE COMMENTED THAT HE HAS NEVER SEEN A TRULY BAD PRODUCTION OF Much Ado, and it would take a perverse imagination to render the scenes between Beatrice and Benedick as anything other than delightful. John Murphy's vision of the play, however, was remarkable for how sweet and frothy a confection it created out of the components of Shakespeare's script. The director commented in the program notes that he set the play in late 1950s Italy, the world of commercial film studios and movie stars as a way of translating the social hierarchies and gender dynamics into a more familiar setting. This updating did require a few script alterations - for example, Don Pedro was referred to several times as a director rather than as a prince. But it also offered an excuse to create a number of wonderfully creative stage moments.

Benedick (a smoothly charming Kevin MacDonald) and his young friends arrived onstage in a convertible, and later several characters chased each other on Vespa scooters. The masquerade ball seemed a perfectly reasonable form of evening entertainment for this glamorous crowd as well as an excuse for the costume designer to show off some very chic frocks. These costumes were particularly well-suited to lively dancing, which included a conga line, a cha-cha, and a deliciously sultry yet snippy tango between Beatrice (a va-va-voom Amber Lewis) and Benedick.

The setting allowed for clever allusions to late 1950 s popular culture. Rather than stopping the play dead, the song "Sigh no more ladies" became a hummable pop song as it was translated into Italian and performed by Antonio (played by David M. Adams) channeling Dean Martin while supported by "Hey nonny nonny" crooning backup singers. And Dogberry (Ashley O'Connell) and his officers - movie lot security guards incapable of figuring out how to use a set of handcuffs - evoked the Three Stooges.

The most notable visual effect, however, was surely simpler than scooter wrangling. At the start of the play, all of the characters wore shades of black, white, and grey while standing among stark black and white sets. Their hair and makeup were even adjusted to suggest the color 
palette of a black and white film. After Benedick overheard Beatrice's lady friends discussing her "love" for him, when he emerged from his hiding place (behind a shower curtain in a bathtub that had been used as a film prop), his collared shirt had "transformed" from a greyscale into a brilliant blue and orange pattern. The lights focused on him similarly became warm and colorful, creating a strong visual contrast when he encountered the still-disdainful Beatrice. Yet after this lady had her own eavesdropping experience (while hiding behind a screen that still made her visible in silhouette), the polka dots on her white sundress were no longer black but a rainbow of bright colors. She even shifted from being a sultry brunette into a Rita Heywood redhead boasting scarlet lips. Love between Beatrice and Benedick literally brought color to the world of the play.

Hero (Parmiss Sehat) and Claudio (Julien Galipeau) brought a different kind of warmth into the production through their youthful simplicity. The production created a lovely opportunity to make their ultimate reconciliation more palatable by having Claudio tearfully speak his epitaph for Hero not to a cold "monument" but to her gauze-draped corpse. His expression of regret at leaving the tomb made sense of Hero's reaction - as soon as he departed, she rose from the bier, hugged her shroud, and smiled after Claudio, satisfied with his expressions of regret. Her unveiling in the final wedding scene thus became as joyful a deception as the tricks that brought Benedick and Beatrice together.

The only weak element in the production was the transformation of Don John, the resentful bastard brother of Don Pedro, into Dona Johnna (played by Laara Sadiq), a gossip columnist. Gender swapping the role was not problematic, but the failure to offer any sense of goal that might result from the character's malevolence - to destroy her brother's reputation? to get salacious content for her newspaper column? - kept the character as flat as her sleek, platinumblonde bob.

Overall, though, it is difficult to think of a lack of motivated malice as a flaw in a comedy. This creative production utilized its resources to bring the significant pleasures of a drive-in movie to an outdoor summer Shakespeare festival. 


\section{Production Details}

\section{General}

Title

Year

Theater Company

Theaters

Start Date

End Date
Much Ado About Nothing

2017

Bard on the Beach

BMO Mainstage (Canada)

2017-06-01

2017-09-23

\section{Cast}

PRINCE DON PEDRO

LORD CLAUDIO

LADY BEATRICE

LORD BENEDICK

DONA JOHNNA

LADY HERO

LEONATO
IAN BUTCHER

JULIEN GALIPEAU

AMBER LEWIS

KEVIN MACDONALD

LAARA SADIQ

PARMISS SEHAT

ANDREW WHEELER

\section{Creatives}

Director
Costume Designer
Scenery Designer And BARd Artistic Associate
Lighting Designer
SOUNd Designer
ChOREOGRAPHy

JOHN MURPHY

Christine Reimer

PAM JOHNSON

GERALD KING

MuRRAY PRICE

TARA Cheyenne Friedenberg 